\title{
Crystal structure of the defect clathrate-I; $\mathrm{Ba}_{8} \mathrm{Ge}_{43}$
}

\author{
W. Carrillo-Cabrera ${ }^{*, I}$, J. Curda ${ }^{\mathrm{II}}$, K. Peters ${ }^{\mathrm{II}}$, S. Paschen ${ }^{\mathrm{I}}$, M. Baenitz ${ }^{\mathrm{I}}$, Yu. Grin ${ }^{\mathrm{I}}$ and H. G. von Schnering ${ }^{\mathrm{II}}$ \\ I Max-Planck Institut für Chemische Physik fester Stoffe, Bayreuther Straße 40, D-01 187 Dresden, Germany \\ II Max-Planck Institut für Festkörperforschung, Heisenbergstr. 1, D-70569 Stuttgart, Germany
}
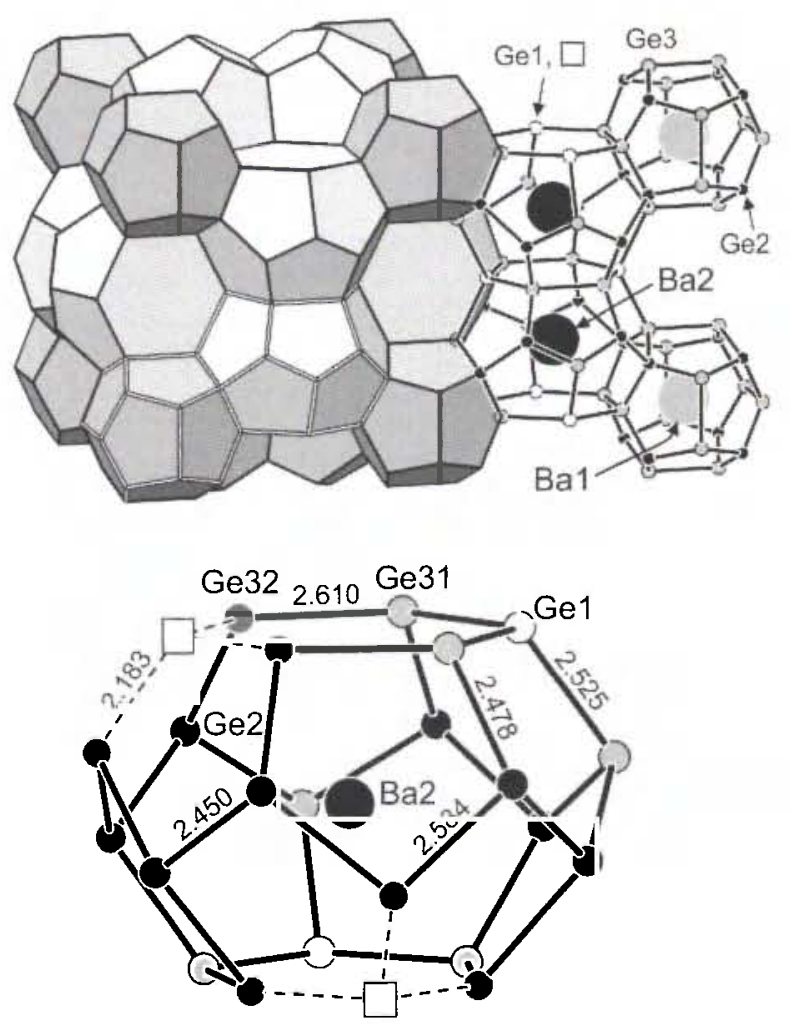

\section{Abstract}

$\mathrm{Ba}_{8} \mathrm{Ge}_{43}$, cubic, $P m \overline{3} n$ (No. 223), $a=10.6565(2) \AA, V=1210.2 \AA^{3}$, $Z=1, R_{\mathrm{gt}}(F)=0.036, w R_{\text {ref }}\left(F^{2}\right)=0.055, T=293 \mathrm{~K}$.

\section{Source of material}

$\mathrm{Ba}_{8} \mathrm{Ge}_{43}$ was prepared as single phase by melting the elements in an open glassy carbon crucible (HF furnace, argon atmosphere) and annealing at $1068 \mathrm{~K}(6 \mathrm{~d})$. The single crystals were obtained from the as-cast sample. The substance is silvery metallic, brittle, relatively stable in air and moisture. EDX analysis of bulk samples resulted in the chemical composition $\mathrm{Ba}_{8.0(1)} \mathrm{Ge}_{42.9(1)}$.

\section{Experimental details}

The lattice parameters were determined from the least-squares refinement of the $2 \theta$ values of 54 reflections $\left(18^{\circ}<2 \theta<100^{\circ}\right.$, powder data). The X-ray powder data were obtained on the sample with nominal composition $\mathrm{Ba}_{8} \mathrm{Ge}_{43}\left(\lambda\left(\mathrm{CuKa}_{1}\right)=1.540598 \AA\right.$; $\mathrm{LaB}_{6}$ standard, $\left.a=4.15695(6) \AA\right)$.

\section{Discussion}

$\mathrm{Ba}_{8} \mathrm{Ge}_{43}$ was first obtained as a by-product of the decomposition of $\mathrm{Ba}_{3} \mathrm{Ge}_{4} \mathrm{C}_{2}$ [1] at $1123 \mathrm{~K}$ (1h) under high pressure (ca. $40 \mathrm{~kb}$ ). The $\mathrm{Ba}_{8} \mathrm{Ge}_{43}$ structure (upper part of the figure) belongs to the clathrate-I type with Pearson symbol $c P(54-3)$. Refined occupancies of $\mathrm{Ge}(1), \mathrm{Ge}(31)$ and $\mathrm{Ge}(32)$ positions resulted in the chemi-

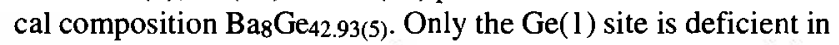
germanium. Consequently, the neighbouring $\mathrm{Ge}(3)$ position splits into the two near sites $\mathrm{Ge}(31)$ and $\mathrm{Ge}(32)$ (Table 2). The latter occurrs only if $\mathrm{Ge}(1)$ is empty. Similar results were obtained for the $\mathrm{A}_{8} \mathrm{Sn}_{44} \square_{2}$ clathrates, $A=K, \mathrm{Rb}, \mathrm{Cs}[2,3]$. A short range ordered model of the vacancies $(\square)$ in the germanium environment of $\mathrm{Ba}(2)$ atoms is shown in the lower part of the figure (atomic distances in $\AA$ ). The investigation of the possible long range ordering in long time annealed samples is in progress. Per formula unit, 31 germanium atoms are fourfold bonded (4b) and 12 germanium atoms in the $\mathrm{Ge}(31)$ sites are threefold bonded (3b). The compound may be formulated as

$\left(\mathrm{Ba}^{2+}\right)_{8}\left((3 \mathrm{~b}) \mathrm{Ge}^{\mathrm{l}}\right)_{12}\left((4 \mathrm{~b}) \mathrm{Ge}^{0}\right)_{31}\left(4 \mathrm{e}^{-}\right)$.

According to this, $\mathrm{Ba}_{8} \mathrm{Ge}_{43} \square_{3}$ is a Zintl phase with a few electrons in not localized antibonding states of the network or in conduction bands. Semimetallic or metallic properties are expected $[4,5]$.

Table 1. Data collection and handling.

\section{Crystal:}

Wavelength:

$\mu$ :

Diffractometer, scan mode:

$2 \theta_{\max }:$

$N(h k l)_{\text {measured }}, N(h k l)_{\text {onique: }}$

Criterion for $l_{\mathrm{obs}}, N(h k l)_{\mathrm{gi}}$.

$N(\text { param })_{\text {refined: }}$

Programs:

Table 2. Atomic coordinates and displacement parameters (in $\AA^{2}$ ).

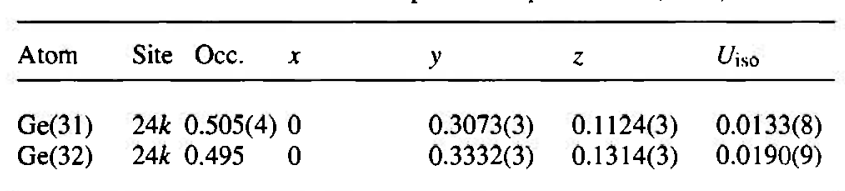

\begin{tabular}{|c|c|c|}
\hline \multicolumn{3}{|c|}{ 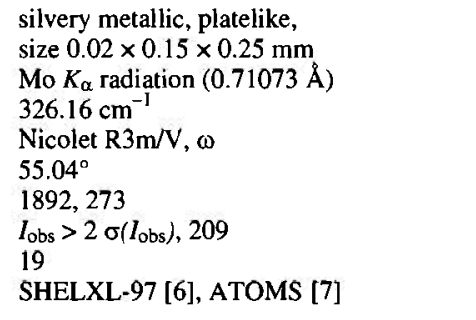 } \\
\hline \multicolumn{3}{|c|}{ and displacement parameters (in $\AA^{2}$ ). } \\
\hline$y$ & $z$ & $U_{\text {iso }}$ \\
\hline $\begin{array}{l}0.3073(3) \\
0.3332(3)\end{array}$ & $\begin{array}{l}0.1124(3) \\
0.1314(3)\end{array}$ & $\begin{array}{l}0.0133(8) \\
0.0190(9)\end{array}$ \\
\hline
\end{tabular}

\footnotetext{
* Correspondence author (e-mail: carrillo@cpfs.mpg.de)
} 
Table 3. Atomic coordinates and displacement parameters (in $\AA^{2}$ ).

\begin{tabular}{|c|c|c|c|c|c|c|c|c|c|c|c|}
\hline Atom & Site & Occ. & $x$ & $y$ & $z$ & $U_{11}$ & $U_{22}$ & $U_{33}$ & $U_{12}$ & $U_{13}$ & $U_{23}$ \\
\hline $\mathrm{Ba}(1)$ & $2 a$ & & 0 & 0 & 0 & $0.0131(4)$ & $U_{11}$ & $U_{11}$ & 0 & 0 & 0 \\
\hline $\mathrm{Ba}(2)$ & $6 d$ & & $1 / 4$ & $1 / 2$ & 0 & $0.0218(8)$ & $0.0368(6)$ & $U_{22}$ & 0 & 0 & 0 \\
\hline $\mathrm{Ge}(1)$ & $6 c$ & $0.488(9)$ & $1 / 4$ & 0 & $1 / 2$ & $0.013(2)$ & $0.014(2)$ & $U_{22}$ & 0 & 0 & 0 \\
\hline $\mathrm{Ge}(2)$ & $16 i$ & & $0.18364(6)$ & $x$ & $x$ & $0.0157(3)$ & $U_{11}$ & $U_{11}$ & $-0.0024(3)$ & $U_{12}$ & $U_{12}$ \\
\hline $\operatorname{Ge}(3)^{a}$ & $24 k$ & & 0 & $0.3196(1)$ & $0.1213(1)$ & $0.0165(6)$ & $0.0373(7)$ & $0.0267(6)$ & 0 & 0 & $0.0166(6)$ \\
\hline
\end{tabular}

a: $\mathrm{Ge}(3)$ is the average position of $\mathrm{Ge}(31)$ and $\mathrm{Ge}(32)$, see Table 2 .

Acknowledgments. The authors thank Dr. R. Ramlau for the EDX analysis.

\section{References}

1. Curda, J.; Carrillo-Cabrera, W.; Schmeding, A.; Peters, K.; Somer, M.; von Schnering, H. G.: Tribarium tetrahedro-Tetragermanide Acetylenide, $\mathrm{Ba}_{3}\left[\mathrm{Ge}_{4}\right]\left[\mathrm{C}_{2}\right]$ : Synthesis, Structure, and Properties. Z. Anorg. Allg. Chem. 623 (1997) 929-936.

2. Baitinger, M.; Grin, Yu.; von Schnering, H. G.: Valence determined defects in the clathrate-I structures of $\mathrm{A}_{8} \mathrm{Sn}_{46-x}$ with $\mathrm{A}=\mathrm{K}, \mathrm{Rb}, \mathrm{Cs}$. $\mathrm{VI}^{\text {th }} \mathrm{Eu}-$ ropean Conference on Solid State Chemistry, Zürich, 1997, Abstract PA116.
3. von Schnering, H. G.; Kröner, R.; Baitinger, M.; Peters, K.; Nesper, R.; Grin, Yu.: Crystal structure of the defect clathrate $\mathrm{Cs}_{8} \mathrm{Sn}_{44} \square_{2}$. Z. Kristallogr. NCS 215 (2000) 205-206.

4. Carrillo-Cabrera, W.; Paschen, S.; Grin, Yu.: Unpublished results.

5. Herrmann, R. F. W.; Tanigaki, K.; Kawaguchi, T.; Kuroshima, S.; Zhou, O.: Electronic structure of $S i$ and Ge gold-doped clathrates. Phys. Rev. B 60 (1999) 13245-13248.

6. Sheldrick, G. M.: SHELXL-97, a program for refining crystal structures. University of Göttingen, Germany 1997.

7. Dowty, E.: Atoms 4.1, A Complete Program for Displaying Atomic Structures. By Shape Software, Kingsport, TN 37663, USA 1998. 